\title{
James Hanrahan, Voltaire and the Parlements of France
}

\section{Peter Balazs}

\section{(2) OpenEdition \\ 1 Journals}

\section{Édition électronique}

URL : http://journals.openedition.org/studifrancesi/6655

DOI : 10.4000/studifrancesi.6655

ISSN : 2421-5856

Éditeur

Rosenberg \& Sellier

\section{Édition imprimée}

Date de publication : 1 septembre 2010

Pagination : 372-373

ISSN : 0039-2944

\section{Référence électronique}

Peter Balazs, "James Hanrahan, Voltaire and the Parlements of France », Studi Francesi [En ligne], 161 (LIV | II) | 2010, mis en ligne le 30 novembre 2015, consulté le 08 janvier 2021. URL : http:// journals.openedition.org/studifrancesi/6655; DOI : https://doi.org/10.4000/studifrancesi.6655

Ce document a été généré automatiquement le 8 janvier 2021.

\section{(c) $($ ) $(9)$}

Studi Francesi è distribuita con Licenza Creative Commons Attribuzione - Non commerciale - Non opere derivate 4.0 Internazionale. 


\title{
James Hanrahan, Voltaire and the Parlements of France
}

\author{
Peter Balazs
}

\section{RÉFÉRENCE}

JAMES HANRAHAN, Voltaire and the Parlements of France, Oxford, Voltaire Foundation, 2009

(SVEC 2009:06), pp. 265.

1 Les rapports de Voltaire avec les Parlements sont traditionnellement décrits en termes conflictuels: comment ce grand Philosophe «défenseur des opprimés» et partisan de la monarchie absolue aurait pu s'accommoder des cours souveraines, usurpant l'autorité royale, exerçant une censure obscurantiste et auteurs - ce qui plus est - de plusieurs condamnations scandaleuses? J. Hanrahan se propose de nuancer les affirmations qu'il juge exagérées au sujet de la haine inexorable que le futur seigneur de Ferney aurait porté aux parlements dès le début de la carrière du philosophe. Cela est d'autant plus nécessaire que ses prédécesseurs - nous dit l'auteur du volume - sont coupables d'avoir considéré-commettant par là un anachronisme inacceptable-la ferveur antiparlementaire qui a caractérisé Voltaire au tournant des années 1760-70 comme une sorte de conviction de principe déterminant la réflexion du philosophe tout au long de sa vie. Seule une étude attentive et surtout contextualisée de l'évolution de sa pensée sur les parlements permettra de dissiper un certain nombre de malentendus. Il convient également de distinguer (comme Voltaire l'a fait) entre les diverses fonctions des cours souveraines: établissements de justice, autorités de censure, organes représentatifs d'une politique anti-absolutiste, etc...

2 L'ouvrage est composé de trois grandes parties. Après une introduction dans laquelle on peut lire des remarques méthodologiques perspicaces portant sur la critique que J. Israel a adressée à Baker, Chartier et d'autres, nous pouvons commencer la lecture de la première grande unité, qui traite de la période d'avant l'affaire Calas. Le jeune Voltaire, auteur de la Henriade, partage les convictions gallicanes des parlementaires. Les 
magistrats qui figurent dans ses œuvres littéraires de jeunesse ne reflètent aucun sentiment antiparlementaire de la part de leur auteur. Quant aux analyses (très bien documentées et fondées sur les résultats des recherches les plus récentes) portant sur la censure, elles montrent que les censeurs royaux et papaux ont donné plus de fil à retordre à Voltaire que ne l'ont fait ceux des parlements. Au niveau strictement politique, les conflits entre la couronne et les parlements au sujet de la bulle Unigenitus n'intéressaient pas outre mesure le philosophe, au moins jusqu'au moment de l'attentat de Damiens. Certes, l'opposition tenace des parlements aux tentatives de réforme fiscale de la couronne n'était pas de nature à lui plaire, mais il faut aussi noter que tout au long de cette période, Voltaire entretenait des relations amicales avec plusieurs magistrats provinciaux, afin de pouvoir jouir en tranquillité de son statut de seigneur de Ferney.

La deuxième partie est consacrée à la présentation des causes célèbres (les affaires Calas, Sirven et La Barre) des années 1760, ou plutôt à leur rôle dans l'évolution des idées de Voltaire sur les parlements. L'auteur note que la bête noire de Voltaire dans les textes et dans sa correspondance produits à l'occasion de ces jugements scandaleux n'était pas tel ou tel parlement, ni d'ailleurs l'institution en général, mais plutôt une notion abstraite et idéologique: le fanatisme. Tandis que la plupart des commentateurs ont cru voir un lien étroit entre ces causes célèbres et la préparation de l'Histoire $d u$ Parlement de Paris (un ouvrage très critique à l'égard des aspirations politiques des cours souveraines et des conceptions historiques qui les sous-tendent), l'auteur est plutôt d'avis que la raison d'avoir écrit un tel ouvrage doit être recherchée dans l'intérêt accru en France pour l'histoire nationale récente. L'étude de l'argumentation de Voltaire dans l'ouvrage en question amène l'auteur à questionner la dichotomie commode qui consiste à opposer Voltaire aux parlements parce que le premier aurait été un fervent partisan de l'absolutisme de Louis XV.

4 La troisième partie commence par une comparaison systématique entre l'Histoire $d u$ Parlement de Paris et le Précis du siècle de Louis XV. Les inconséquences et les contradictions relevées dans les deux ouvrages demandent une explication: lequel des deux ouvrages reflète le véritable point de vue de leur auteur sur l'histoire récente de la monarchie française? Le chapitre terminal analyse les réactions de Voltaire à la réforme Maupeou de 1771. L'auteur montre que le soutien que Voltaire accorde au chancelier ne s'explique pas uniquement par ses convictions de partisan d'un «absolutisme éclairé», au contraire, un certain nombre de considérations pratiques (notamment ses intérêts d'affaires et ses idées humanitaristes) ont également influé sur ses prises de position - ce qui peut être lu comme la conclusion de cet excellent ouvrage, très critique à l'égard des interprétations «absolutistes» de la monarchie des Lumières. 